Revista Destaques Acadêmicos, Lajeado, v. 10, n. 4, 2018. ISSN 2176-3070

DOI: http://dx.doi.org/10.22410/issn.2176-3070.v10i4a2018.2083

http://www.univates.br/revistas

\title{
A MODELAGEM MATEMÁTICA COMO PROPOSTA DE ENSINO: PLANTIO DE ALFACES, UMA PRÁTICA COM ALUNOS DO $3^{\circ}$ ANO DO ENSINO FUNDAMENTAL
}

\author{
Daniela Brunetto Moreira Cesar ${ }^{1}$, Lawrence Mota Galvão², \\ Márcia Fleck Valduga ${ }^{3}$, Ítalo Gabriel Neide ${ }^{4}$, Márcia Jussara Hepp Rehfeldt ${ }^{5}$
}

Resumo: Este artigo relata uma atividade de Modelagem Matemática, na perspectiva de estratégia de ensino, aplicada em uma turma de terceiro ano do Ensino Fundamental, de uma escola da rede pública situada em um dos municípios da Região da Serra Gaúcha. Com o objetivo de tornar o processo de ensino prático e significativo, utilizou-se uma situação do cotidiano dos alunos, relacionada ao tema "Alimentação Saudável", cuja proposta era responder ao seguinte questionamento: Quantas mudas de alface serão necessárias para o preenchimento total de um canteiro? Neste problema, a modelagem matemática se apresentou como uma possibilidade de aprimorar técnicas e estratégias no que diz respeito ao ensino da matemática. A partir da análise desta atividade, permitese proferir a evidência de características como o interesse, motivação e empenho por

1 Mestranda do Curso em Ensino de Ciências Exatas pela Universidade do Vale do Taquari UNIVATES. Graduada em Ciências Exatas pela Universidade do Vale do Taquari UNIVATES. Professora. E-mail: danibru@universo.univates.br

2 Mestre em Ensino de Ciências Exatas pela Universidade do Vale do Taquari UNIVATES. Graduado em Matemática pela Universidade Federal do Amazonas - UFAM. Professor. E-mail:galvaogalvaomota@gmail.com.

3 Mestre em Ensino de Ciências Exatas pela Universidade do Vale do Taquari UNIVATES. Graduada em Ciências Exatas pela Universidade de santa Cruz do Sul - UNISC. Graduada em Matemática pela UNIASSELVI. Professora. E-mail: dariovalduga@gmail.com

4 Pós Doutor pela Universität Duisburg-Essen. Doutor em Ciências pela Universidade Federal do Rio Grande do Sul - UFRGS. Mestre em Física pela Universidade Federal do Rio Grande do Sul - UFRGS. Bacharel em Física pela Universidade Federal do Rio Grande do Sul - UFRGS. Professor. E-mail: italo.neide@univates.br

5 Doutora em Informática na Educação pela Universidade Federal do Rio Grande do Sul UFRGS. Mestre em Administração pela Universidade Federal do Rio Grande do Sul- UFRGS. Especialização em Educação Matemática e Gestão Universitária pela Universidade Federal do Rio Grande do Sul - UFRGS. Licenciatura em Ciências - Habilitação em Matemática pela Universidade Federal do Rio Grande do Sul - UFRGS. Professora. E-mail: mrehfeld@univates.br 
parte dos alunos, que a partir da resolução do problema proposto, produziram modelos matemáticos que corroboram a defesa desta potencial estratégia de ensino.

Palavras-chave: Modelagem Matemática. Medidas. Horta Escolar. Estratégia de Ensino.

\section{INTRODUÇÃO}

Este trabalho se propõe em relatar e discutir a resolução de um problema real proposto com uso da Modelagem Matemática. Para isso, usamos como exemplo, o plantio de alfaces em canteiro de uma horta escolar pertencente a uma escola pública, situada no Vale dos Vinhedos, município de Bento Gonçalves - RS. A região do Vale dos Vinhedos, distrito do município de Bento Gonçalves, é ocupada por descendentes de imigrantes italianos que lá se instalaram a partir de 1876 , onde, inicialmente, tinham a atividade agrícola bastante variada.

No começo, eles contavam com lavouras de milho, trigo, cevada e feijão, mas com o passar do tempo, estas foram substituídas por parreirais para cultivo de uva. Hoje, as famílias têm suas atividades econômicas voltadas para a produção de vinhos e sucos naturais, instalados em plantas fabris consideradas modernas para a região. Também atuam na produção de biscoitos, doces, entre outras iguarias, as quais buscam satisfazer os paladares dos mais variados e exigentes turistas, além de proporcionar cenários que trazem um pouco da região da Toscana, na Itália.

Partindo desta realidade e, tendo como proposta a utilização de uma prática envolvendo a Modelagem Matemática como metodologia de ensino, de acordo com Metelski e Francisco (2008, p. 7), a Modelagem Matemática faz

[...] com que o conteúdo torne-se significativo para o aluno e ele consegue aplicá-lo fora da sala de aula. Com o ensino partindo, de preferência, de temas de interesse dos alunos, do seu cotidiano, da sua problemática que pode aguçar o interesse pela solução do problema e diminuir a resistência pela matemática.

Esta metodologia permite que o aluno tenha liberdade na escolha das ferramentas matemáticas a partir dos seus conhecimentos pré-existentes. $\mathrm{O}$ objetivo deste trabalho é apresentar e discutir os resultados obtidos em uma prática de Modelagem Matemática a partir do tema alimentação saudável, cujo problema envolvia o plantio de alfaces em uma horta escolar, envolvendo alunos do $3^{\circ}$ Ano do Ensino Fundamental.

Desta forma, torna-se importante caracterizar a Modelagem Matemática e, sob forma de complementar a atividade proposta, trazer alguns aspectos relacionados à Alimentação Saudável - Horta Escolar e Sistema de Medidas, os quais apresentaremos nas seções a seguir. 


\section{MODELAGEM MATEMÁTICA}

Quando analisamos diferentes contextos históricos, relacionados a teorias pedagógicas, podemos observar distintas concepções de determinados modelos, que emergiram diante das necessidades e dos problemas vividos em cada etapa de desenvolvimento da sociedade. Frente às mudanças que surgem no campo social, caracterizado pelo desenvolvimento industrial e tecnológico vividos na contemporaneidade, observa-se uma série de implicações em se tratando de processos educativos. Atrevemo-nos a dizer, que de uma forma geral, o 'produto' gerado dentro das escolas, ainda hoje é um 'produto', dissociado da realidade vivenciada pelo educando, impossibilitando-o de ter visões diferenciadas, críticas e pensantes, deixando-o na condição, apenas de reprodutor.

De acordo com Gadotti (2000, p. 8),

Seja qual for a perspectiva que a educação contemporânea tomar, uma educação voltada para o futuro será sempre uma educação contestadora, superadora dos limites impostos pelo Estado e pelo mercado, portanto, uma educação muito mais voltada para a transformação social do que para a transmissão cultural.

Conforme o autor nos mostra, qualquer que sejam as sendas que a educação seguir, deverá sobrepujar as adversidades no intuito de mudança do tecido social. Mas para que isso aconteça será necessário o docente buscar uma metodologia que proponha a construção de conhecimentos, assumindo um compromisso de formar um cidadão crítico, reflexivo e autônomo, que colabore no processo de ensino aprendizagem. Em concordância pela mudança nas práticas pedagógicas, Gentili $(1995$, p. 25) nos alerta que uma metodologia de ensino mal escolhida,

[...] compromete a transformação da sociedade, já que não há questionamentos e nem pensamentos críticos, os homens e mulheres apenas serão capazes de repetir o que lhe foi repassado em qualquer disciplina, o que desenvolve apenas a memória e a retenção de informações. [Nos parece que] trabalhar o pensamento crítico e reflexivo fica em segundo plano, de forma aos alunos não perceberem todo processo alienatário e excludente presente na sociedade capitalista.

Segundo o autor, sem trabalhar a criticidade dos educandos, eles serão meros reprodutores de informações, impossibilitando assim, conexões que os livrem de processos que possam excluí-los do meio social em que vivem. Para isso, uma metodologia de ensino adequada às suas necessidades educacionais é imperativa. Para que isso seja uma realidade, assim como atender os desafios impostos pela nossa sociedade atual, o profissional da área da matemática deve 
pensar em um ensino contextualizado, que tenha compromisso com a realidade social e cultural, capaz de atender suas necessidades cotidianas.

Como possibilidade de aproximar o educando a sua realidade, através de um ensino contextualizado, que busca trazer aproximação da Matemática ao aluno e dos problemas por ele enfrentados, busca-se a Modelagem Matemática como uma importante metodologia de ensino, que torna o ensino de Matemática não só prazeroso e satisfatório ao aluno, mas que também lhe tenha sentido.

Nas últimas três décadas intensificaram-se as produções acadêmicas sobre Modelagem Matemática, onde podemos alçar aqui alguns autores como: Jonei. C. Barbosa; Rodney C. Bassanezi; Maria S. Biembengut; Dionísio Burak; E. C. Ferruzzi; Ubiratan D’Ambrósio, entre outros. Estes autores têm se posicionado no campo da matemática com fecunda bibliografia, voltada para o uso da Modelagem Matemática como recurso, estratégia e/ou metodologia de ensino. Os autores discutem a aplicabilidade da Modelagem Matemática, partindo do mais elementar nível de ensino ao mais elevado e complexo, sendo que esta se mostra capaz de fazer interligações do campo teórico da matemática, com as situações do cotidiano.

Para Bassanezi (2004, p. 24) a "Modelagem consiste, essencialmente, na arte de transformar situações da realidade em problemas matemáticos, cujas soluções devem ser interpretadas na linguagem usual". Desta forma, podemos perceber que a arte de modelar consiste em trazer problemas existentes na vida real, no intuito de transformá-lo em um modelo que facilite sua compreensão do que está sendo abordado.

Corroborando a este pensamento, Barbosa (2001, p. 6) destaca, que "a Modelagem é um ambiente de aprendizagem no qual os alunos são convidados a indagar e/ou investigar, por meio da Matemática, situações oriundas de outras áreas da realidade".

A possível relação entre a Matemática e a realidade, diferencia-se para alguns teóricos com relação à Modelagem Matemática. Biembengut e Hein (2005, p. 13) argumentam que, "genericamente, pode-se dizer que a Matemática e realidade são dois conjuntos disjuntos e a Modelagem é um meio de fazêlos interagir". Bassanezi (2004, p. 24) contribui dizendo que esta relação entre a Matemática e a realidade nas atividades de Modelagem, sempre se dará por aproximação: "[...] estamos sempre trabalhando com aproximações da realidade, ou seja, [...] estamos laborando sobre representações de um sistema ou parte dele". Para tanto, não cabe aqui fazer definições de Matemática e realidade, entretanto, é importante mencionar que, ao trabalhar com atividades que fazem referência a realidade, não concordamos em considerar esta área à parte da realidade assumindo assim, a mesma postura de Barbosa (2001), que reforça a ideia de que a Matemática não pode ser considerada fora da realidade, mas sim, parte dela. 
Fitando as visões destes autores, mesmo com diferenças na abordagem da Modelagem Matemática para uso em sala de aula com os educados é admissível perceber a importância da possibilidade de usá-la na abordagem de problemas que sejam peculiares aos educandos, possivelmente causando assim, maior interesse no estudo da Matemática.

Em se tratando de sua aplicação, faz-se necessário ter em mente, que a Matemática usada para construir modelos, deve ter a finalidade de entender e compreender uma determinada realidade. Conforme D’Ambrósio (2001, p. 23),

[...] Modelagem Matemática caracteriza-se por meio da dinâmica de realidade/reflexão sobre a realidade, que resulta uma ação planejada, estabelecendo assim um ciclo vital: realidade informa indivíduo que processa e executa uma ação que modifica a realidade que informa indivíduo [...]

Neste entendimento, a Modelagem Matemática é um instrumento que permite ao educando exercer seu poder de análise da realidade, dando a ele a capacidade de desenvolver um conhecimento reflexivo e crítico para que modifique a realidade que o submerge. Esse conhecimento mais críticoreflexivo ganha um forte apoio da Modelagem Matemática, que surge a partir da realidade e a ela retorna, como uma possibilidade de intervir nesta realidade. E, para se chegar aos modelos matemáticos, cabe salientar que o educando possui uma forte ligação aos seus conhecimentos pré-existentes, pois Biembengut e Hein (2007, p. 12-13) defendem que:

Se o conhecimento matemático restringe-se a uma matemática elementar como aritmética e/ou medidas, o modelo pode ficar delimitado a esses conceitos. Tanto maior o conhecimento matemático, maiores serão as possibilidades de resolver questões que exijam uma matemática mais sofisticada. Porém, o valor do modelo não está restrito à sofisticação matemática.

Ou seja, quanto maior for o conhecimento matemático do educando, maior será a precisão dos resultados, que possibilitará em uma maior aproximação da realidade. Entretanto, se o nível de conhecimento não for elevado, modelos mais simples irão emergir, podendo desta forma, distanciarse um pouco da realidade dando apenas uma impressão espectral, mas sem perder seu valor.

Nesse enredo cabe ao professor desenvolver uma metodologia de forma criativa, que utilize a Modelagem Matemática como metodologia de ensino capaz de oferecer o desenvolvimento de atitudes positivas, que conduzam a uma melhor aprendizagem. Desta forma, é essencial que a Modelagem Matemática desperte no aluno o interesse e a motivação, a fim de desenvolver 
seu raciocínio como cidadão crítico e, sobretudo, com a compreensão do papel sociocultural que a Matemática desempenha.

\section{ALIMENTAÇÃO SAUDÁVEL - HORTA ESCOLAR}

Sendo a escola um local privilegiado para desenvolver ações que visam promover questões relacionadas à saúde e hábitos saudáveis, produziu-se uma atividade que, aliando teoria e prática, procurou contribuir para a formação de bons hábitos alimentares aos estudantes.

A construção de uma horta dentro de um ambiente escolar possibilita aos estudantes o desenvolvimento de conhecimentos relacionados desde o cultivo e benefícios, além de visualizar as ações do homem junto ao meio ambiente.

Na óptica de Morgado (2006, p. 9), "a horta inserida no ambiente escolar pode ser um laboratório vivo que possibilita o desenvolvimento de diversas atividades pedagógicas em educação [...] unindo teoria e prática de forma contextualizada, auxiliando no processo de ensino-aprendizagem". Ou seja, possibilidade que torna o processo de ensino e aprendizagem muito mais significativo.

Segundo Nogueira (2005), a horta na escola pode servir como fonte de alimentação e atividades didáticas. Oferece grandes vantagens às comunidades envolvidas, como a obtenção de alimentos de qualidade a baixo custo, como também no envolvimento de programas relacionados à alimentação e saúde, que podem ser desenvolvidos nas escolas.

Como é possível perceber, realizar trabalhos acadêmicos utilizando uma horta inserida no ambiente escolar só tende a ser um meio eficaz para o ensino e aprendizagem. Muitos assuntos podem surgir a partir do seu planejamento, como: a disposição de espaço, tipo de solo e sua preparação, formas de plantio, tipo de cultivo, variedade, quantidade, entre outros. Também é preciso planejar a manutenção destas hortaliças até o momento de sua colheita, salientando que tais cuidados podem também ser compartilhados com os próprios educandos.

Partindo destas concepções, buscou-se aproveitar a horta já existente na escola, que permitiu o plantio de alfaces, tendo em vista que estes vegetais são consumidos diariamente na merenda escolar. Partindo disso, foi possível oferecer a oportunidade de discutir e ver na prática conteúdos abordados em sala de aula, como sistemas de medidas, quatro operações fundamentais da Matemática, entre outros assuntos que puderam ser trabalhados correlacionados ao tema alimentação saudável, gerando situações diferenciadas de aprendizagem.

A esse respeito, Meksenas (1991) salienta que o professor ao dar uma aula, não desenvolve apenas o conteúdo da área de conhecimento, mas propicia ao educando a oportunidade de compreender o ambiente em que está inserido. 


\section{SISTEMA DE MEDIDAS}

Para medir o comprimento e a largura de alguma coisa, os homens, nos primórdios da agricultura, utilizavam partes de seu corpo como unidades de medida, por exemplo: a jarda, a polegada, o palmo, o passo e o pé. Pequenas distâncias eram medidas com os pés ou com os passos e grandes distâncias eram medidas pela contagem dos dias de caminhada. Podemos citar os antigos babilônios, os egípcios, gregos e romanos que segundo Centurión (1994) lançavam mão da padronização de diversas medidas com o intuito de suprir suas necessidades. Somente na segunda metade do século XVII as medidas tiveram, a priori, sua concepção com John Wilkins na Royal Society de Londres, que concebeu o Sistema Internacional de Unidade - SI (do francês Système international d'unités), um sistema de medidas utilizado e conhecido mundialmente.

Segundo Toledo e Toledo (1997, p. 271), medir é "comparar grandezas de mesma natureza, sendo o resultado de cada medição expresso por um número e por uma unidade de medida". Atualmente, muitos são os instrumentos utilizados para medir, e, para ilustrar esse cenário e potencializar a discussão acerca dessa temática estes autores também salientam que:

[...] a criança não se preocupa com medições até aproximadamente 9 anos. Muito antes, contudo, ela já envolve com medidas, embora de modo bastante informal. Por exemplo: ao verificar se é mais alta que o colega, na fila; se a quantidade de refrigerante que recebeu é igual à do irmão; etc. Algumas situações, porém, exigem maior cuidado, como nos casos em que é fundamental a precisão das medidas. Aí torna-se necessário o conceito de medida e suas aplicações (TOLEDO E TOLEDO, 1997, p. 27).

Partindo deste pressuposto, que a criança tem uma melhor noção de medidas a partir dos nove anos, durante a atividade do plantio de alfaces, esta atividade permitiu explorar e aprimorar diferentes processos e instrumentos de medida.

\section{PROPOSTA DE ATIVIDADE}

Considerando que a Escola já dispõe de um espaço destinado à uma horta escolar, onde já se cultivavam vegetais para o próprio consumo com canteiros pré-existentes, propomos através da Modelagem Matemática, que os estudantes da turma de terceiro Ano do Ensino Fundamental, respondessem ao seguinte questionamento: quantas mudas de alface serão necessárias para o preenchimento total deste canteiro?

Entendendo-se a Modelagem Matemática, como uma metodologia no ensino da Matemática, introduzimos esta atividade a partir do tema "Alimentação Saudável". Tal atividade, baseou-se no seguinte roteiro: Introdução e discussão 
sobre o tema proposto (Alimentação Saudável); Apresentação do problema a ser modelado; Análise; Estudo e Aplicação de diferentes sistemas de medida; O uso das operações fundamentais na matemática, para subsidiar a atividade; Estudo da relevância de uma alimentação saudável; Regras de cultivo de hortaliças.

Ao término desta tarefa, os estudantes realizaram uma avaliação oral, sobre o tema proposto e da forma como este foi realizado. Salienta-se que a professora titular da turma prosseguiu neste assunto em duas outras aulas, a qual também, juntamente aos estudantes, prosseguiu com os cuidados e com a manutenção do canteiro cultivado.

\section{RESULTADOS E DISCUSSÕES}

Dando início a atividade proposta, conforme destacam Biembengut e Hein (2007), utilizamos da informalidade para abordar o tema "Alimentação Saudável" (Figura 1).

Figura 1 - Conversa informal, 2016

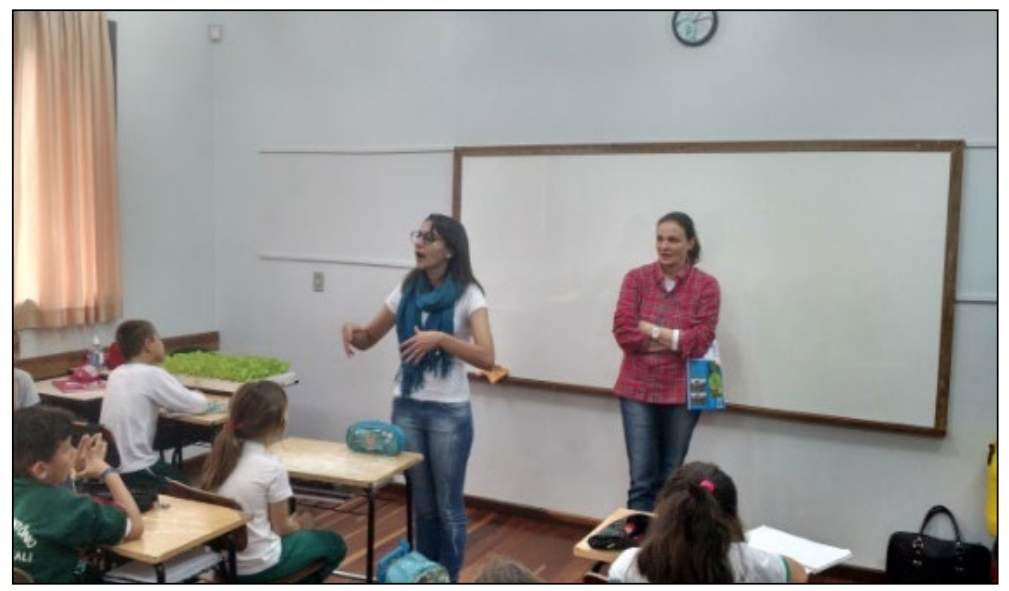

Fonte: Dos autores, (2016).

Na sequência, apresentou-se ao grande grupo a situação problema, que foi recebida com entusiasmo, motivação e certa curiosidade sobre o andamento da mesma. Partindo disto, iniciamos o planejamento questionando sobre o que seria necessário para iniciarmos o cultivo de um canteiro, bem como, para realizar o plantio de verduras e legumes em uma horta. Neste momento os alunos se manifestaram com euforia, já que de certa forma vivenciam essa realidade tanto na escola como em suas casas, por residirem na zona rural. Assim, puderam contribuir de forma muito positiva com ideias sobre a construção de canteiros, tipo de terra, adubos, ferramentas, mudas de verduras e/ou legumes, sementes, etc. 
Após problematizar e abordar em sala de aula a parte teórica envolvendo a construção do canteiro, trouxemos aos alunos, como sugere Barbosa (2001), a possibilidade de pôr em prática o cultivo de um canteiro de verduras. Este, por sua vez, já estava devidamente preenchido com terra e adubo, sendo necessário realizar somente o plantio das mudas de alface, outrora escolhida dentro do cardápio escolar de hortaliças que integram a alimentação dos alunos.

Para uma melhor observação na execução e acompanhamento dos Modelos Matemáticos propomos a subdivisão da turma em grupos, como recomendam Bienbengut e Hein (2007), sendo cada grupo foi composto por quatro estudantes. Após a constituição dos mesmos, os designamos em: Grupo A; Grupo B; Grupo C e Grupo D, para futura análise dos resultados.

Considerando-os mais familiarizados com a metodologia, lhes informamos que tinham à disposição para o plantio do canteiro 120 mudas de alface. Prosseguindo a atividade, realizamos os seguintes questionamos: Quantas mudas de alface precisaríamos para preencher o canteiro? Qual espaço caberia a cada grupo para o plantio? E como faríamos para dar início ao plantio?

O grupo A, que era composto somente por alunas, reuniu-se de modo que ficassem mais afastadas dos demais grupos, sendo que após discutirem por breve instante, disseram que o primeiro passo necessário para responder tais questionamentos, seria medir o canteiro. O grupo B, logo em seguida, disse que poderia usar as mãos o "palmo" para medir. O grupo A discordou desta colocação, dizendo que seria melhor a utilização de uma régua, fita métrica ou trena, colocando a estes que o resultado seria "mais correto", perguntandonos assim, se possuíamos algum destes instrumentos para lhes auxiliar. Confirmamos que sim, e disponibilizamos uma régua, uma trena e uma fita métrica, Figuras 3 e 4.

Figura 3 - Fita métrica 2016

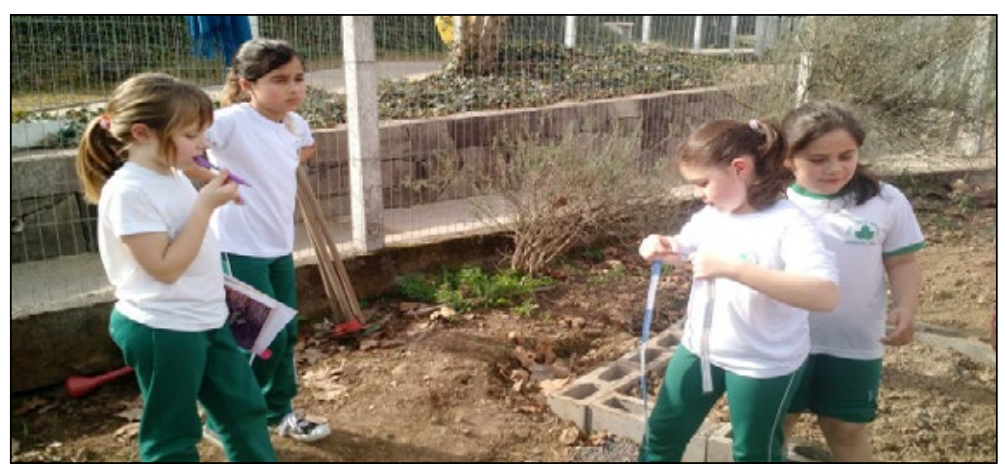

Fonte: Dos autores (2016). 
Figura 4 - Fita métrica 2016

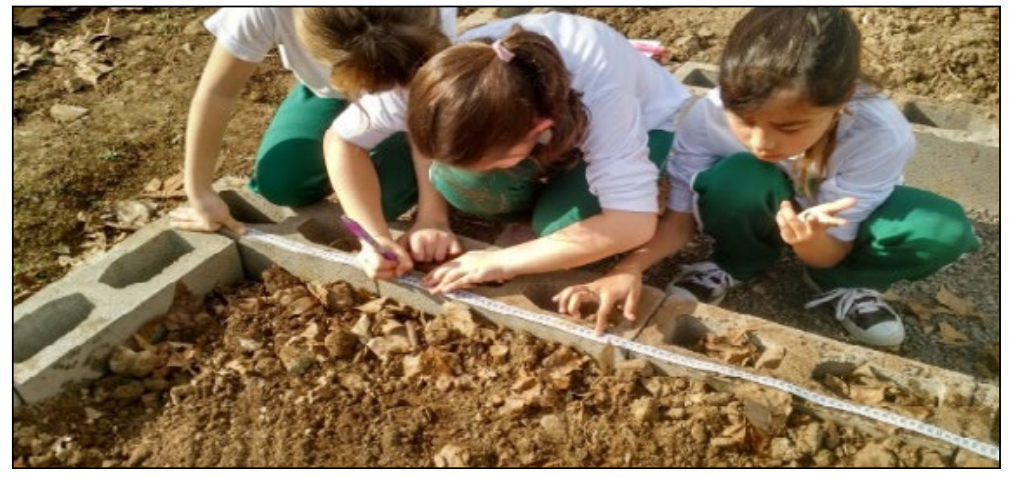

Fonte: Dos autores (2016).

Em seguida, alunos dos Grupos B e C proferiram que não seria necessário, pois o canteiro era todo cercado com blocos de concreto, assim sendo, era só contar os blocos. Os deixamos livres para definir qual seria o melhor processo utilizado, porém todos os grupos fizeram a contagem dos blocos, os quais chegaram ao total de 32 unidades em seu comprimento e 3,5 em sua largura.

No entanto, o grupo A não convencido em adotar essa metodologia de apenas contar os blocos que margeavam as medidas do canteiro, permaneceu em sua empreitada de fazer uso da trena métrica, confirmando a informação que fora suscitada pelos grupos B e C, após a divisão do valor do comprimento do canteiro pela quantidade de grupos.

Vale salientar, que a insistência das alunas do grupo A em usar os instrumentos para aferir a medida do canteiro, influenciou os alunos do grupo B e C. Estes, mesmo após terem usado a metodologia de contarem os blocos de concreto, que constituíam o canteiro, também fizeram uso da trena para apenas confirmar o que já haviam inicialmente encontrado. Cabe salientar também que os modelos matemáticos emergidos, representam o conhecimento matemático pré-existentes, sendo estes intrínsecos a cada aluno/grupo, como afirmam Bienbengut e Hein (2007).

Os integrantes do grupo D tiveram pouca participação na atividade e não propuseram algo diferente na realização da tarefa. Diferentemente dos grupos A e B que demostraram celeridade e euforia de formas distintas com a novidade que lhes estava sendo proposto. Contudo, essa diferença de ritmo não trouxe problemas na percepção e no desenvolvimento da atividade por parte dos alunos do grupo $\mathrm{D}$, considerando que cada aluno tem um ritmo de aprendizagem própria.

Mesmo apresentando uma postura mais tímida, os alunos do grupo D, ainda assim, demonstraram forte participação na deliberação de como iniciar o plantio das alfaces, etapa subsequente, onde fora alçado a ideia de medir a 
extensão do canteiro. A esta situação, diferentes modelos de aferir medidas foram sendo discutidos entre os grupos, que apesar de estarem divididos em grupos, pensaram e agiram de forma conjunta, utilizando a fita métrica para determinarem as dimensões do canteiro: 12 metros de comprimento por 1 metro de largura.

Aferida a medida do canteiro, os grupos começaram a se questionar com relação à quantidade de mudas que seriam plantadas por cada grupo e qual o espaço que caberia a cada um dentro da extensão do canteiro. Neste momento, todos estavam absortos na resolução destes dois questionamentos. Enquanto discutiam, uma aluna do grupo A, salientou em seu grupo, que seria necessário apenas dividir a medida da extensão do canteiro pela quantidade de grupos, e assim rapidamente o fizeram, chegando ao espaço que caberia a cada grupo, um resultado de três metros.

Em seguida, o grupo B, baseando-se no montante de blocos de concreto, chegou à conclusão que o espaço destinado a cada grupo, seria o equivalente a oito blocos. Estes também auxiliaram na separação de cada espaço destinado aos grupos, que após serem demarcados com uma pequena pedra, foram conferidos pelo grupo A. Na sequência, em posse das mudas de alface, os grupos reportaram-se a nós, questionando qual seria o espaçamento ideal entre as mudas. Partindo destas indagações, devolvemos a eles a seguinte pergunta: Qual espaço que vocês consideram ideal entre as mudas de alface, sendo que todo o canteiro deverá ser preenchido?

Os integrantes do grupo A e B, rapidamente contaram o total de mudas e passaram a discutir qual a distância ideal entre elas, para ter um plantio uniforme. Pudemos observar neste momento, que as discussões e os modelos matemáticos que estavam surgindo, advinham da divisão do espaço destinado pelo total de mudas de alface.

Nesta etapa, os grupos C e D fizeram o uso mais intuitivo da noção de espaço, pegando as mudas da alface e as distribuindo no espaço disponível, descobrindo assim uma distância uniforme entre elas, de aproximadamente 30 centímetros. Tal medida, logo fora ratificada também pelos grupos A e B. Quando estes foram questionados sobre a forma de cálculo utilizada, um dos alunos do grupo B relatou que leu em um livro, o qual abordava tipos de cultivo no campo, que o espaçamento ideal entre hortaliças seria de 30 centímetros e uma profundidade de $7 \mathrm{~cm}$. Assim, conseguiram chegar à soma de 30 mudas, total necessário para preencher o espaço que lhes cabia no canteiro.

Observando os alunos, pudemos averiguar empenho, curiosidade e muita disposição para execução do que lhes fora proposto. Os mesmos não mediram esforços, demostraram trabalho coordenado e participativo, sem nenhum atrito de ideias ou mesmo de comportamento, conseguindo assim, executar a empreitada de plantar o canteiro das alfaces. 
No tocante aos modelos matemáticos emergidos, pudemos observar modelos simples, os quais fizeram o uso das quatro operações básicas da matemática. Pudemos perceber ainda, uma certa dificuldade no uso destas operações pelos integrantes do grupo C e D, contudo, se propuseram a buscar por meio de outros caminhos, como a observação do espaço medido com as próprias mudas de alface, a solução para aquele determinado problema.

Também foi possível perceber a matemática sendo trabalhada de maneira prazerosa e agradável, através de comentários positivos durante o andamento da atividade, da manipulação de dados, com ênfase para as unidades de medidas, trouxeram resultados satisfatórios. A esse respeito, Bassanezi (2007, p. 15) profere que:

[...] matemática agradável é àquela que se faz sentir tanto elegante e funcional, como formal e aplicável e, ainda, bonita e útil. [...] uma matemática interessante e útil, que não se distancia demasiadamente do conteúdo programático básico existente, pelo menos enquanto tal conteúdo não for repensado/reorganizado.

Naturalmente, conseguir essa elegância e funcionalidade buscando a aplicabilidade formal da matemática não é algo trivial, pois requer equilíbrio, demanda tempo, dedicação e conhecimento teórico formal por parte do aluno, que está manipulando a matemática. Ainda conforme este autor,

[...] conseguir este equilíbrio [...] pode parecer [...] inatingível, principalmente quando consideramos a formação inadequada do professor e os fatores sócio-político-econômicos que envolvem todo o processo, cujos efeitos sentidos em nossas salas de aula [...] [entretanto a aplicação da] [...] modelagem matemática, já tem sido defendida por muitos educadores (BASSANEZI 2007, p. 15).

Assim, em nossa compreensão, a Modelagem Matemática quando utilizada como meio de estratégia de ensino, possibilita mais leveza ao ensino e engajamento de todos os envolvidos no processo de ensino e de aprendizagem. Já que esta, traz a "[...] oportunidade para os alunos indagarem situações por meio da Matemática sem procedimentos fixados previamente e com possibilidades diversas de encaminhamento (BARBOSA, 2001, p. 5)".

\section{CONSIDERAÇÕES FINAIS}

As reflexões que trazemos neste artigo, são resultados de uma atividade relacionada a Modelagem Matemática, aplicada a uma turma de alunos pertencentes ao Terceiro Ano do Ensino Fundamental.

Partindo dos resultados evidenciados através da prática, os quais foram realizados com presteza e dedicação em um ambiente colaborativo de troca de informações e construção de conhecimento, entendemos que a Modelagem 
Matemática, tratada nesta proposta como metodologia de ensino, torna-se uma poderosa ferramenta de trabalho.

Argumentos como "motivação, facilitação da aprendizagem, preparação para utilizar a matemática em diferentes áreas, desenvolvimento de habilidades gerais de exploração e compreensão do papel sócio-cultural da matemática" (BARBOSA, 2004, p. 73), foram constatados, o que implica na relevância desta metodologia.

Também foi possível observar a manipulação de dados e a aplicação de conhecimentos matemáticos de forma correta, o que possibilitou aos estudantes a solução do problema e a validação de seu modelo matemático, que mesmo sendo modelos simples, foram considerados satisfatórios à esta atividade e à etapa a qual este grupo pertence.

Desta forma, defendemos que a Modelagem Matemática enquanto estratégia de ensino, torna-se um grande aliado no processo de ensino e aprendizagem da matemática. Diferentes situações problema, com referência à realidade, podem ser expostos e trabalhados de maneira agradável em uma construção colaborativa, sem causar perturbações ásperas aos estudantes, principalmente quando utilizam aspectos teóricos da matemática.

\section{REFERÊNCIAS}

BARBOSA, J. C. Modelagem Matemática e os professores: a questão da formação. Bolema - Boletim de Educação Matemática, n. 15, 2001.

BARBOSA, J. C. Modelagem Matemática: O que é? Por que? Como? Revista Veritati, n. 4, p. 73- 80, 2004. Disponível em: <www.educadores.diaadia.pr.gov.br/arquivos/.../ Matematica/artigo_veritati_jonei.pdf> Acesso em: 30 julho. 2016.

BASSANEZI, R. C. Ensino-aprendizagem com Modelagem Matemática. São Paulo: Contexto, 2004.

BASSANEZI, R. C. Modelagem Matemática: uma disciplina emergente nos programas de formação de professores. UNICAMP. IMECC, Departamento de Matemática. 1999. Disponível em: < http:/ /www.ime.unicamp.br/ biomat/ bio9art_1.pdf > Acesso em: 24 julho. 2016.

BIEMBENGUT, M. S.; HEIN, N. Modelagem Matemática no Ensino. São Paulo: Contexto, 2005.

BIEMBENGUT, M. S.; HEIN, N. Modelagem Matemática no Ensino. São Paulo: Contexto, 2007.

BRASIL. Ministério da Educação (MEC). SEB, Brasília, 2006. Orientações curriculares para o ensino médio: Ciências da Natureza, Matemática e suas Tecnologias. 
Disponível em: < http:/ / portal.mec.gov.br/seb/arquivos/pdf/book_volume_02_ internet.pdf $>$ Acesso em: 25 de julho. 2016.

CENTURIÓN, M. Conteúdo e metodologia da matemática: números e operações. São Paulo: Scipione, 1994.

D'AMBRÓSIO, U. Educação Matemática: da teoria à prática. São Paulo: Papirus, 2001.

GADOTTI, M. Perspectivas atuais da educação. Porto Alegre: Artes Médicas, 2000.

GENTILI, P. Pedagogia da exclusão. $4^{\text {a }}$ Ed., Petrópolis. Vozes, 1995.

MEKSENAS, P. Aprendendo Sociologia: A Paixão de Conhecer a Vida. $6^{a}$ ed. Loyola. São Paulo. 1991.

METELSKI, C. R.; FRANCISCO, R. Modelagem Matemática: Uma proposta de atividade desenvolvida na $6^{\text {a }}$ série do ensino fundamental - Guarapuava, Brasil, 2008. Disponível em: < http://www.diaadiaeducacao.pr.gov.br/portals/pde/ arquivos /695-4.pdf > Acesso em: 21 julho. 2016.

MORGADO, Fernanda da Silva. A Horta Escolar na Educação Ambiental e Alimentar: experiências do projeto horta viva nas escolas municipais de Florianópolis. Centro de Ciências Agrárias. Universidade Federal de Santa Catarina, Florianópolis, 2006.

NOGUEIRA, W. C. L. Horta na escola: uma alternativa de melhoria na alimentação e qualidade de vida. In: ENCONTRO DE EXTENSÃO DA UFMG, 8, 2005, Belo Horizonte. Anais... Belo Horizonte: UFMG, 2005, 48p.

SCHELLER, Morgana. Modelagem Matemática na iniciação científica: Contribuições para o ensino médio técnico - Porto Alegre, Brasil, 2009. Disponível em < http:/ / www.lume.ufrgs.br/bitstream/handle/10183/17711/000723556.pdf?...1 > Acesso em: 25 julho. 2016.

TOLEDO, Marília: TOLEDO, Mauro. Didática da Matemática: como dois e dois: a construção da matemática. São Paulo: FTD, 1997. 